\title{
Why can an environmental policy tax promote growth through the channel of education?
}

\author{
André Grimaud* \\ Université de Toulouse I (GREMAQ, IDEI and LERNA) and ESCT \\ Frederic Tournemaine ${ }^{\dagger}$ \\ School of Economics \\ The University of Chicago-UTCC Research Center \\ University of the Thai Chamber of Commerce
}

November, 2006

\begin{abstract}
This paper examines the implications of an environmental policy for growth performances. We develop a model where growth is driven by human capital accumulation. Firms invest in research to develop new technologies to reduce their pollution emissions and education is treated as product which not only enhances the productivity of individuals but also enters in their preferences. We find that a tighter environmental policy can promote growth. The reason is that a higher tax on pollution drives the prices of goods whose production is polluting up. This, in turn, enhances the willingness of individuals to acquire education.
\end{abstract}

Keywords: environment, education, knowledge, growth, economic policy. JEL Classification: O31, O34, O41, Q28.

*Address: 21 allée de Brienne 31000 Toulouse France, phone: +33 (0)5 6112 86 04, fax: +33 (0)5 61 1286 37, e-mail: grimaud@cict.fr

${ }^{\dagger}$ Corresponding author: 126/1 Vibhavadee-Rangsit Road, Dindaeng, Bangkok, 10400, Thailand, phone: +66 (0)40 8269 89, e-mail: frederic.tournemaine@uc-utcc.org 


\section{Introduction}

There are disparities of conclusions concerning the impact of environmental regulation on economic growth. On the one hand, authors such as Ligthart and van der Ploeg (1994), Grimaud (1999) suggest that an environmental policy reduces economic growth. On the other hand, Porter and Van der Linde (1995), Bovenberg and Smulders (1995), Hart (2004) among others explain that a better quality of the environment is compatible with a higher level of growth.

Motivated by this debate, we attempt to shed some light on the mechanisms through which environmental policies can affect growth performances. In this paper, we assume the government's intervention which aims at obtaining a cleaner environment by using a policy instrument to influence the pollution emissions of firms. We show that an environmental policy can promote growth when it acts through the channel of education. The intuition is that a tighter policy causes an augmentation of the price of goods whose production is polluting. In the meantime, the relative price of acquiring education becomes lower. Thus, individuals choose to accumulate more human capital which boosts the long-run economic growth rate. Indeed, to conduct the analysis we develop a growth model in which human capital accumulation is the ultimate engine of growth. There are two reasons that justify this choice of formalization. First, the importance of the role played by education for growth and development has been recognized for more than a decade in economic theory (see the pioneering paper of Lucas, 1988). Second, it allows us to focus in a simple way on the implication for growth of an environmental policy.

Closely related to our analysis are the papers of van Ewijk and van Wijnbergen (1995) and Oueslati (2002). They develop growth models with pollution externalities based on Lucas' setting and find that environmental policy can have positive growth effects. However, the mechanisms through which the economic policy acts differs from our paper. In the former setting, pollution affects negatively the production of education. Thus, a cleaner environment allows individuals to accumulate more human capital which benefits to economic growth. In the latter, a higher environmental tax gives incentives to firms to augment their abatement activities which leads to a diminution of the final output net of abatement. In turn, individuals reduce their leisure time and acquire more skills in order to overcome the lower level of consumption.

Furthermore, in this paper, we go further and augment the basic structure of these 
analyses in two ways. First, we investigate the idea that education is a product that not only enhances the productivity of individuals on the labour market but also affects their level of utility. Although, this notion has been considered by some economists, it has not been formalized in growth models. For instance, Schultz (1963) explains that the benefits to education can be divided into three components: first, an investment component which comes from the increase in an individual's wealth; second, a present consumption component such as the utility derived from attending class; and a future consumption component coming from the fact that education improves the ability of an individual to consume other goods in life (see e.g. footnote 3, pp. 570 in Lazear, 1977). Alstadsaeter (2004), Boonprakaikawe and Tournemaine (2006) point out that individuals acquire education not only for its implied wages reward, but also for its induced non-pecuniary returns for which they are willing to pay. The non-pecuniary returns to education consist of the joy of learning new things, meeting new people, moving to a new city or a new country and so on.

Second, we develop a model that integrates a specific research and development (R\&D) activity. That is, our framework comes within the scope of the new generation of growth models based on R\&D (e.g. Romer, 1990; Grossman and Helpman, 1991; Aghion and Howitt, 1992). Specifically, firms that produce goods, simultaneously engage in the development of new technologies (ideas, new pieces of knowledge) that are used to reduce pollution emissions. This idea is in line with Carraro and Siniscalco (1994) who argue that, following an environmental policy, big corporations tend to invest in research to develop new technologies that are less polluting rather than to reduce their production. It should be mentioned that in the fourth section of their paper, van Ewijk and van Wijnbergen (1995) consider the possibility of a separate research process aiming at reducing pollution. However, they assume that new technologies are improved through a learning process similar to the educational one: the decisions to invest in the learning process are realized by individuals rather than by firms.

In contrast with the standard R\&D-based literature, in our model, the new pieces of knowledge (i.e. the non rival or non-depletable goods according to the textbook definition, for instance that of Mas-Colell, Whinston and Green, 1995, ch. 11 or Scotchmer, 2005, ch. 2) are not embedded inside intermediate goods. They are directly used in production processes and protected by patents. This can be seen as a formalization of ideas that have been developed for years by various authors such as Arrow (1962), Scotchmer (1991), 
Dasgupta et al (1996), Gallini and Scotchmer (2003) but which have not found their way in growth models.

In addition to greatly simplify the technical analysis, we believe that such formalization allows us to account for the recent evolution of intellectual property law: since the mideighties, one observes that pieces of knowledge are directly patented. It is now possible to obtain patents for databases, software, business plans (see Scotchmer, 1999). Scotchmer (2005) and Quah $(1997,2001)$ emphasize the distinctive properties of these goods as they label them respectively as 'information goods' for the former and 'knowledge-products' for the latter. They argue that their properties resemble to those of knowledge. This is because the "private" goods embedding knowledge in the case of new technologies have an almost nonexistent marginal cost of production (CD-ROM) or even a zero one (an on-line copy). It is therefore akin to a public good and almost consubstantial with the idea itself. When we characterize the equilibrium, we state the problem as if the piece of knowledge itself, the public good, were patented.

The remainder of the paper is organized as follows. In Section 2, we set out the model. In Section 3, we characterize the equilibrium and discuss its properties regarding to environmental policy changes. We conclude in Section 4. The Appendix is gathered in Section 5 .

\section{The model}

We consider a model in continuous time. There are four types of goods: differentiated consumption goods, $X_{j}$, produced by an exogenous number of sectors $(j=1, \ldots, N)$, each one comprising $Q_{j}$ identical firms $\left(q_{j}=1, \ldots, Q_{j}\right)$; pollution emissions, $E$, which are coming from the production of differentiated goods; human capital, $H$, accumulated by individuals; and knowledge, $Z$, produced through research activities. A continuum of pieces of knowledge (i.e. information goods or knowledge products) constitutes the total stock of knowledge at every point in time $t$. A piece of knowledge is an indivisible, infinitely-lived, differentiated, public good. It can be a scientific report, a database, or a software algorithm. Technologies and preferences are described as follows.

In sector $j$, firm $q_{j}$ produces a quantity $X_{q_{j} t}$ of differentiated good $j$, with the technology 


$$
X_{q_{j} t}=A H_{q_{j}}^{X},
$$

where $A>0$ is a constant productivity parameter and $H_{q_{j} t}^{X}$ is the quantity of human capital employed for the production of the differentiated good. Simultaneously, the firm runs in-house $\mathrm{R} \& \mathrm{D}$ to produce new pieces of knowledge. We denote by $Z_{q_{j} t}$ the stock of knowledge produced by firm $q_{j}$ until date $t$. New pieces of knowledge are produced with the technology

$$
\dot{Z}_{q_{j} t}=\delta H_{q_{j} t}^{Z}\left(Z_{t}\right)^{\phi}
$$

where $\delta>0$ is a productivity parameter, $\phi<1$ is a measure of the knowledge spillover in research, $H_{q_{j} t}^{Z}$ is the amount of human capital employed to conduct research and $Z_{t}=\sum_{j=1}^{N} \sum_{q_{j}=1}^{Q_{j}} Z_{q_{j} t}$. The technology (2) is closed to the one introduced by Jones (1995). However, it accounts for the fact that human capital is a key ingredient to make research which is established for years in economic literature: for instance, Nelson and Phelps (1966) explain that education facilitates adoption and implementation of new technologies. It has been used by several authors in R\&D-based models with human capital accumulation (see Arnold, 1998; Funke and Strulik, 2000; Blackburn et al, 2000; Dalgaard and Kreiner, 2001; Strulik, 2005). The idea is that individuals are not skillful researchers by birth. They need to be educated. Perpetual growth of knowledge is possible despite diminishing returns in research because human capital provides the necessary increasing efforts needed to sustain growth.

Knowledge is used to reduce pollution caused by the production of differentiated goods. We assume that the flow of pollution emissions of firm $q_{j}$ is given by

$$
E_{q_{j} t}=\left(X_{q_{j} t}\right)\left(Z_{t}\right)^{-\beta}
$$

where $\beta>0$. It should be noted that most environmental problems are stock ones. Even though carbon dioxide emissions are retained by the atmosphere, some of these are also seized by oceans (and forests) and trapped for long periods of time. Despite this feature, we treat pollution as a flow for two reasons. First, one can consider that it is a reasonable approximation if the depreciation rate of pollution stock is high (see Schou, 2002). Second, from a technical point of view, it simplifies the analysis without altering the main insight of the paper. As a final remark one should observe that the technology (3) is closed to 
the one used by Stokey (1998), Aghion and Howitt (1998) and Grimaud (1999) in which $Z_{t}$ is a measure of the dirtiness of the technology.

In our model, once a new piece of knowledge is produced, it is directly used to reduce pollution emissions. Such assumption must be interpreted as a short-cut. Indeed, one could assume that once a new idea has occurred it is embedded in a physical good which is then used to reduce pollution emissions as formalized in the standard R\&D-based literature (e.g. Romer, 1990; Grossman and Helpman, 1991; Aghion and Howitt, 1992). In this case, we could assume that the physical good is produced using human capital. Although this kind of formalization may appear more realistic, it would complicate the technical analysis of the model without adding new insights: we would add another market in the analysis but the reduction of pollution emissions would still be the outcome of increases in the stock of knowledge.

There is a mass $[0,1]$ of identical individuals. There is no population growth so that all aggregate variables can be interpreted as per capita quantities. Individuals own human capital that they allocate between working activities (production of differentiated goods, research) and education which takes place through a human accumulation process. Following Lucas (1988), we assume that the total stock of human capital, $H_{t}$, evolves through time according to

$$
\stackrel{\bullet}{H}_{t}=\psi H_{t}^{H}
$$

where $\psi>0$ is the productivity of education and $H_{t}^{H}$ is the quantity of human capital devoted to education.

Individuals derive utility from the consumption of differentiated goods, their level of education, and a clean environment, i.e. pollution has nefarious effects on their welfare. Preferences are represented by

$$
U=\int_{0}^{\infty}\left[\ln \left[\sum_{j=1}^{N}\left(c_{j t}\right)^{\alpha}\right]^{1 / \alpha}+\varepsilon \ln \left(H_{t}\right)-\omega \ln E_{t}\right] e^{-\rho t} d t,
$$

where $0<\alpha<1, \varepsilon \geq 0, \omega>0, c_{j t}$ is the per-capita purchase of each differentiated good $j, E_{t} \equiv \sum_{j=1}^{N} \sum_{q_{j}=1}^{Q_{j}} E_{q_{j} t}$ is the total flow of pollution emissions and $\rho$ is the rate of time preferences, where $0<\rho<\psi$ : the productivity of education must be large compared with the rate of time preferences to ensure positive growth at equilibrium.

The parameter $\varepsilon$ can be interpreted as the desire for education. If $\varepsilon>0$, education is treated as a consumption good. Individuals obtain emotional benefits through school- 
ing. This can be the pleasure to learn new things, to have new friends. This can be the possibility to consume goods, like a concert of classical music, which require a certain level of education to be appreciated. Or, this can be the satisfaction to obtain a degree at university: education is a mean for people to advertise their skills. This allows them to obtain better jobs and reach a social position in the society. ${ }^{12}$ We will see that considering education as a consumption good has an important implication for the role that an environmental policy plays for the determination of the long-run level of growth. If $\varepsilon=0$, however, the level of education has no effect on the level of utility of individuals. This is the basic case analyzed in growth literature.

Since the whole amount of every differentiated good is consumed, one has

$$
c_{j t}=X_{j t}
$$

where $X_{j t}=\sum_{q_{j}=1}^{Q_{j}} X_{q_{j} t}$. Finally, the human capital constraint is

$$
H_{t}=H_{t}^{X}+H_{t}^{Z}+H_{t}^{H}
$$

where $H_{t}^{X}=\sum_{j=1}^{N} \sum_{q_{j}=1}^{Q_{j}} H_{q_{j} t}^{X}$ and $H_{t}^{A}=\sum_{j=1}^{N} \sum_{q_{j}=1}^{Q_{j}} H_{q_{j}}^{A}$.

\section{Equilibrium}

This Section tackles three objectives. The first and main one is to study the effects on the long-run economic growth rate of an environmental policy charged on polluting firms. To reach this goal, we assume the government's intervention by means of a tax $\tau_{t}$ charged on the amount of pollution emissions.

The second objective is to characterize an equilibrium with complete markets where knowledge is directly priced and privately funded. In contrast with the standard R\&Dbased literature, we assume that new pieces of knowledge are directly protected by infinitely lived patents. It would be possible to assume that patents expire after a finite period. Barro and Sala-i-Martin (1995, ch. 6) analyse the consequences of such assumptions in a standard R\&D-based model. The idea is that there is an erosion of the monopoly

\footnotetext{
${ }^{2}$ Lazear (1977) explains that school attendance, which is necessary to acquire skills, is a 'psychic cost' for individuals. In the absence of any wealth augmentation effects, most individuals would not acquire any education. He estimates that education causes disutility to individuals, i.e. it is a 'bad'. For simplicity, in this paper, we avoid this possibility.
} 
power. The authors show that the main insights of the model are still valid under this assumption. However, it complicates the analysis because there are two stocks of knowledge to consider: the one whose patents have expired and the one whose patents have not. Assuming that patents are infinitely-lived allows us to keep the analysis simple and focus on the key feature of the model.

As knowledge is a public good, there are difficulties of funding knowledge in a decentralized economy. Two types of problems arise. The first ones are related to the possibility of verifying which agents use knowledge; they are linked to the possibility of excluding agents that do not pay to use knowledge; they concern the problems of information on the marginal profitability of knowledge for an agent. These problems prevent innovators from appropriating the entire amount of the surplus they create. It should be mentioned that if new ideas were embedded in physical goods as in the basic R\&D-based literature, it would be easier to verify which agents are using the new technologies. As explained in Section 2, we justify our assumption by the fact that our formalization is a short-cut which simplifies the analysis.

A second type of problem comes from the non-convexity of technologies using knowledge as a productive factor (see (2) and (3)). As in a competitive market the payment of private factors fully exhausts revenues, firms are unable to pay for the public good they use. ${ }^{3}$ To solve this problem of existence, either we must assume that knowledge is publicly funded which is not realistic, or we must introduce imperfect competition. In this paper, we characterize a dynamic general equilibrium with Cournot competition and free entry. ${ }^{4}$ We assume that the $N$ markets for differentiated goods, $X_{j t}$, are imperfectly competitive. By selling their goods at a price $p_{j t}$ which is greater than the marginal cost of production, firms get resources that allow them to buy knowledge. We assume that there is free entry on each differentiated good market, i.e. profits are zero. Then, the payment of knowledge appears as a fixed cost for each firm. The number of firms, $Q_{j t}$,

\footnotetext{
${ }^{3}$ See for instance Kaizuka (1965), Sandmo (1972), Manning et al. (1985), Feehan (1989), Romer (1990), Jones (2003) for more details on this point.

${ }^{4}$ Papers by Smulders and Van de Klundert $(1995,1997)$ and Peretto $(1998,1999 a, 1999 b)$ which use a similar model to ours introduce also imperfect competition. However, they do not consider the possibity of patenting and pricing knowledge.

In a model dealing with polluting ressources, Grimaud and Rouge (2005) use the same kind of approach in the sense that they assume that new pieces of knowledge are directly patented. But in their paper, research is publicly funded.
} 
that composes each differentiated sector $j$ is determined by using the free entry condition. For the sake of simplicity, we assume that $Q_{j t}$ is a continuous variable.

We assume that knowledge is traded using bilateral contracts between inventors and users. To keep the analysis simple, and because it does not yield new insights for the purpose of the paper, we assume that sellers are able to extract the whole willingnesses to pay of all buyers, i.e. there are no problem of verification, exclusion and information. We denote by $\widetilde{\pi_{q_{j}}}$ the profit of firm $q_{j}$ without payment of knowledge. The willingness to pay of firm $q_{j}$ to use a piece of knowledge at date $t$ is $v_{q_{j} t}=\partial \widetilde{\pi_{q_{j}}} / \partial Z_{t}$. The price that it pays to use a piece of knowledge from $t$ to infinity is then $V_{q_{j} t}=\int_{t}^{\infty} v_{q_{j} s} e^{-\int_{t}^{s} r_{u} d u} d s$, where $r_{u}$ denotes the interest rate. The payment perceived by any firm for the sale of a piece of knowledge, i.e. the value of a piece of knowledge, is $V_{t}=\int_{t}^{\infty} v_{s} e^{-\int_{t}^{s} r_{u} d u} d s$, where $V_{t}=\sum_{j=1}^{N} \sum_{q_{j}=1}^{Q_{j t}} V_{q_{j} t}$ and $v_{s}=\sum_{j=1}^{N} \sum_{q_{j}=1}^{Q_{j t}} v_{q_{j} s}$. Differentiating the expression of $V_{t}$ with respect to time yields the usual condition: $r_{t}=v_{t} / V_{t}+g_{V_{t}}$, where $g_{z}$ denotes the growth rate of any variable $z .^{5}$

Finally, the market for human capital whose price is normalized to one $\left(w_{t}=1\right)$ and the financial market are perfectly competitive. Formally, an equilibrium is defined as follows:

Definition 1 : An equilibrium with Cournot competition and free entry is a set of profiles of number of firms $\left(\left\{Q_{j t}\right\}, j=1, \ldots, N\right)$, of quantities of goods $\left(\left\{X_{q_{j} t}\right\},\left\{H_{q_{j} t}^{X}\right\},\left\{H_{q_{j}}^{Z}\right\}\right.$, $\left.\left\{Z_{q_{j} t}\right\}, q_{j}=1, \ldots, Q_{j t}, j=1, \ldots, N,\left\{H_{t}^{H}\right\}\right)$, and of prices $\left(\left\{v_{q_{j} t}\right\},\left\{V_{q_{j}}\right\}, q_{j}=1, \ldots, Q_{j t}\right.$, $\left.j=1, \ldots, N,\left\{p_{j t}\right\}, j=1, \ldots, N,\left\{r_{t}\right\}\right)$ such that:

- individuals maximize utility;

- firms maximize profits;

- the human capital market and the financial market are perfectly competitive and clear;

- on each differentiated good market, there is Cournot competition with free entry;

- pieces of knowledge are traded using bilateral contracts.

The third objective is to derive an implementation of the optimal balanced growth

\footnotetext{
${ }^{5}$ To extend the analysis to the case in which sellers extract only a fraction of the willingnesses to pay, one can assume that innovators know that the willingness to pay of firm $q_{j}$, to use an innovation at $t, v_{q_{j}} t$, belongs to the set $\left[\underline{v}_{q_{j} t}, \overline{v_{q_{j}}}\right]$ which is the support of a cumulative distribution function denoted by $\Phi()$. If sellers choose $\widehat{v_{q_{j} t}}$ such that $\widehat{v_{q_{j}} t}<v_{q_{j} t}$, they get $\widehat{v_{q_{j}} t}$ with probability $1-\Phi\left(\widehat{v_{q_{j} t}}\right)$. If they choose $\widehat{v_{q_{j} t}}$ such that $\widehat{v_{q_{j}} t}>v_{q_{j} t}$, they get zero with probability $\Phi\left(\widehat{v_{q_{j}}}\right)$. The instantaneous expected gain of sellers is then: $\widehat{v_{q_{j}} t}\left[1-\Phi\left(\widehat{v_{q_{j}} t}\right)\right]$. Thus the price that maximizes this expression is $\widehat{v_{q_{j} t}}=\left[1-\Phi\left(\widehat{v_{q_{j}}}\right)\right] / \Phi^{\prime}\left(\widehat{v_{q_{j} t}}\right)$.
} 
path of the model. There are two distortions at equilibrium: pollution emissions and imperfect competition. To neutralize the effects of these distortions, two economic policy tools are then necessary. The first one is the tax on pollution emissions, $\tau_{t}$, introduced previously. By choosing an appropriate environmental policy, the government can obtain an optimal flow of pollution. The second policy tool consists of a subsidy for the demands of differentiated goods, $\sigma_{j t}, j=1, \ldots, N$. This aims at removing the effects caused by the competition "a la Cournot" to get optimal demands for differentiated goods.

We assume that the environmental policy and the subsidies for the demand of differentiated goods are funded through a lump-sum transfer, $T_{t}$, from individuals. We suppose that the budget constraint of the government is balanced at each moment. We now turn to the behavior of agents.

\subsection{Behavior of agents}

\subsubsection{Individuals}

The representative individual chooses plans for consumption, $c_{j t}$, wealth, $B_{t}$, and human capital, $H_{t}$. He/she maximizes (5) subject to the law of motion of human capital (4), and the budget constraint $\dot{B}_{t}=r_{t} B_{t}+w_{t}\left(H_{t}-H_{t}^{H}\right)-\sum_{j=1}^{N}\left(1-\sigma_{j t}\right) p_{j t} c_{j t}+T_{t}$ (recall that $w_{t}$ is equal to one). Since knowledge, $Z_{t}$, is the only asset of the firms, the total stock of wealth is $B_{t}=Z_{t} V_{t}$. The current-value Hamiltonian to this problem is:

$$
\begin{aligned}
C V H= & \ln \left[\sum_{j=1}^{N}\left(c_{j t}\right)^{\alpha}\right]^{1 / \alpha}+\varepsilon \ln H_{t}-\omega \ln E_{t}+ \\
& \lambda_{t}\left[r_{t} B_{t}+\left(H_{t}-H_{t}^{H}\right)-\sum_{j=1}^{N}\left(1-\sigma_{j t}\right) p_{j t} c_{j t}-T_{t}\right]+\xi_{t} \psi H_{t}^{H} .
\end{aligned}
$$

The first order conditions are: $\partial C V H / \partial c_{j t}=0, \partial C V H / \partial H_{t}^{H}=0, \partial C V H / \partial B_{t}=$ $-\dot{\lambda}_{t}+\lambda_{t} \rho, \partial C V H / \partial H_{t}=\dot{\xi}_{t}+\xi_{t} \rho$. The transversality conditions are: $\lim _{t \rightarrow \infty} \lambda_{t} B_{t} e^{-\rho t}=0$, and $\lim _{t \rightarrow \infty} \xi_{t} H_{t} e^{-\rho t}=0$. Some manipulation gives the following conditions:

$$
\begin{gathered}
\frac{\left(c_{j t}\right)^{\alpha-1}}{\sum_{j=1}^{N}\left(c_{j t}\right)^{\alpha}}=\lambda_{t}\left(1-\sigma_{j t}\right) p_{j t}, \\
\xi_{t} \psi=\lambda_{t} \\
r_{t}+\frac{\dot{\lambda}_{t}}{\lambda_{t}}=\rho
\end{gathered}
$$




$$
\frac{\varepsilon}{\xi_{t} H_{t}}+\frac{\lambda_{t}}{\xi_{t}}+\frac{\dot{\xi}_{t}}{\xi_{t}}=\rho .
$$

Using (8), one gets the aggregate demand function for each consumption good $j$ : $c_{j t}=D_{t}\left[\left(1-\sigma_{j t}\right) p_{j t}\right]^{1 /(\alpha-1)}$, where $D_{t}=\sum_{k=1}^{N}\left(1-\sigma_{k t}\right) p_{k t} c_{k t} / \sum_{k=1}^{N}\left[\left(1-\sigma_{k t}\right) p_{k t}\right]^{\alpha /(\alpha-1)}$. Using the resource constraint, $X_{j t}=c_{j t}$ (see equation (6)), the inverse demand function for differentiated good $j$ is:

$$
p_{j t}=\frac{\left(D_{t}\right)^{1-\alpha}\left(\sum_{q_{j}=1}^{Q_{j t}} X_{q_{j} t}\right)^{\alpha-1}}{\left(1-\sigma_{j t}\right)} .
$$

Combining (8) and (10), one gets the usual Keynes-Ramsey rule:

$$
r_{t}=(1-\alpha) g_{c_{j t}}+g_{\Omega_{t}}+g_{p_{j t}}+g_{\left(1-\sigma_{j t}\right)}+\rho,
$$

where $g_{\Omega_{t}}$ is the growth rate of $\Omega_{t}=\sum_{j=1}^{N}\left(c_{j t}\right)^{\alpha}$.

Combining (8), (9), (10) and (11), one gets:

$$
\psi+\frac{\varepsilon \psi\left(1-\sigma_{j t}\right) p_{j t} \sum_{j=1}^{N}\left(c_{j t}\right)^{\alpha}}{H_{t}\left(c_{j t}\right)^{\alpha-1}}=r_{t} .
$$

Note that the first term on the left hand side of (14), $\psi$, can be interpreted as the pecuniary part of the return to education. It corresponds to the productivity gain that individuals obtain when they allocate an additional unit of human capital to education. This allows individuals to get a higher wage income. The second term, $\varepsilon \psi(1-$ $\left.\sigma_{j t}\right) p_{j t} \sum_{j=1}^{N}\left(c_{j t}\right)^{\alpha} /\left[H_{t}\left(c_{j t}\right)^{\alpha-1}\right]$, is the non-pecuniary part of the return to education. It comes from the utility that individuals derive from the consumption of education. It is equal to zero if the desire for education, $\varepsilon$, is zero. We will see in Section 3.3 that environmental policy changes alter long-run growth through their effects on the non-pecuniary part of the return to education, i.e. through the willingness of individuals to acquire skills.

\subsubsection{Firms}

Firms have two activities: 1) they produce and sell differentiated goods on an imperfect market (competition "a la Cournot"); 2) simultaneously, they produce and sell knowledge. Each time firm $q_{j}$ maximizes $\widetilde{\pi_{q_{j} t}}=p_{j t} X_{q_{j} t}-\tau_{t} p_{j t} E_{q_{j} t}-H_{q_{j} t}^{X}+V_{t} \dot{Z}_{q_{j} t}-H_{q_{j} t}^{Z}$, subject to the technologies $X_{q_{j} t}=A H_{q_{j} t}^{X}$ (see equation (1)) and $\ddot{Z}_{q_{j} t}=\delta H_{q_{j} t}^{Z}\left(Z_{t}\right)^{\phi}$ (see equation (2)), the inverse demand function $p_{j t}=\left(D_{t}\right)^{1-\alpha}\left(\sum_{q_{j}=1}^{Q_{j t}} X_{q_{j} t}\right)^{\alpha-1} /\left(1-\sigma_{j t}\right)$ (see equation (12)) 
and the flow of emissions of pollution $E_{q_{j} t}=\left(X_{q_{t j}}\right)\left(Z_{t}\right)^{-\beta}$ (see equation (3)). After substitutions, one has the following program: $\max . \widetilde{\pi_{q_{j} t}}=X_{q_{j} t}\left\{\left(D_{t}\right)^{1-\alpha}\left(\sum_{q_{j}=1}^{Q_{j t}} X_{q_{j} t}\right)^{\alpha-1}[1-\right.$ $\left.\left.\tau_{t}\left(Z_{t}\right)^{-\beta}\right] /\left(1-\sigma_{j t}\right)-A^{-1}\right\}+V_{t} \delta H_{q_{j} t}^{Z}\left(Z_{t}\right)^{\phi}-H_{q_{j} t}^{Z}$.

The first order condition with respect to $X_{q_{j} t}$ leads to

$$
X_{j t}=D_{t}\left\{\frac{A\left[1-\tau_{t}\left(Z_{t}\right)^{-\beta}\right]\left[1+(\alpha-1) X_{q_{j} t} /\left(X_{j t}\right)\right]}{\left(1-\sigma_{j t}\right)}\right\}^{\frac{1}{1-\alpha}} .
$$

This equation implicitly yields the best response of firm $q_{j}$ to the choice of production of differentiated good $j$ of the others.

The first order condition with respect to $H_{q_{j} t}^{Z}$ yields:

$$
V_{t} \delta\left(Z_{t}\right)^{\phi}=1
$$

The willingness to pay at time $t$ to use a piece of knowledge at $t$ is:

$$
\left.v_{q_{j} t}=\partial \widetilde{\pi_{q_{j} t}} / \partial Z_{t}=\beta \tau_{t}\left(D_{t}\right)^{1-\alpha}\left(X_{j t}\right)^{\alpha-1} X_{q_{j}} t Z_{t}\right)^{-\beta-1} /\left(1-\sigma_{j t}\right)+V_{t} \phi \delta H_{q_{j} t}^{Z}\left(Z_{t}\right)^{\phi-1} .
$$

The term $v_{q_{j} t}$ is composed of two parts. The first one, $\beta \tau_{t}\left(D_{t}\right)^{1-\alpha}\left(X_{j t}\right)^{\alpha-1} X_{q_{j} t}\left(Z_{t}\right)^{-\beta-1}$ $/\left(1-\sigma_{j t}\right)$, is the willingness to pay to use a piece of knowledge at time $t$ to reduce pollution emissions. The second one, $V_{t} \phi \delta H_{q_{j} t}^{Z}\left(Z_{t}\right)^{\phi-1}$, is the willingness to pay to use a piece of knowledge at time $t$ to make research. We recover, here, the public good nature of knowledge inside the firm: each unit of knowledge is used twice by each firm.

The free entry condition on the market of the differentiated good implies

$$
\pi_{q_{j} t}=\widetilde{\pi_{q_{j} t}}-V_{q_{j} t} \dot{Z}_{t}=0, \forall q_{j}, \forall j
$$

where $V_{q_{j} t} \dot{Z}_{t}$ represents the payment of knowledge of firm $q_{j}$.

\subsection{Symmetric equilibrium and characterization of the steady- state}

We now focus on a symmetric equilibrium at steady-state, i.e. on paths along which the growth rate of any variable, the shares of human capital denoted respectively by $l^{X} \equiv H_{t}^{X} / H_{t}, l^{Z} \equiv H_{t}^{Z} / H_{t}, l^{H} \equiv H_{t}^{H} / H_{t}$, and the number of firms in each sector, $Q$, are constant. 
Definition 2 A symmetric equilibrium is characterized by a number of firms in each sector $j$, quantities, prices and rates of subsidy for the demands of differentiated goods that are identical for all $q_{j}$ and for all $j: Q_{j}=Q$ for all $j, X_{q_{j}}=X_{j} / Q=X_{t} / Q$, $l_{q_{j}}^{X}=l_{j}^{X} / Q=l^{X} /(N Q), l_{q_{j}}^{Z}=l_{j}^{Z} / Q=l^{Z} /(N Q), Z_{q_{j} t}=Z_{j t} / Q=Z_{t} /(N Q), E_{q_{j} t}=$ $E_{j t} / Q=E_{t} /(N Q)$, for all $q_{j}$ and for all $j ; p_{j t}=p_{t}, v_{q_{j} t}=v_{j t} / Q=v_{t} /(N Q), V_{q_{j} t}=$ $V_{j t} / Q=V_{t} /(N Q)$ for all $q_{j}$ and for all $j, \sigma_{j t}=\sigma_{t}$ for all $j$.

Proposition 1 summarizes the results we get. The proof of this Proposition shows that the existence of a steady-state equilibrium requires that the term $\tau_{t}\left(Z_{t}\right)^{-\beta}$ is constant over-time. Thus, we assume that the government chooses a growth path for the tax on pollution such that $g_{\tau}=\beta g_{Z}$ at any moment. This implies that $\tau_{t}\left(Z_{t}\right)^{-\beta} \equiv \tau_{0}\left(Z_{0}\right)^{-\beta}$ for all $t$, where $\tau_{0}$ and $Z_{0}$ denote respectively the initial values of $\tau_{t}$ and $Z_{t}$. Furthermore, the rate of subsidy for the demand of differentiated goods is constant at any moment: $\sigma_{t}=\sigma$ for all $t$.

Proposition 1 At steady-state, the symmetric dynamic general equilibrium with Cournot competition and free entry is characterized by a set of quantities, prices, growth rates and a number of firms in each sector that take the following values:

Quantities:

$$
\begin{gathered}
l^{H}=\frac{\varepsilon \psi(1-\sigma)+(\psi-\rho)\left[1-\tau_{0}\left(Z_{0}\right)^{-\beta}\right]}{\psi\left[1-\tau_{0}\left(Z_{0}\right)^{-\beta}\right]+\varepsilon \psi(1-\sigma)}, \\
l^{Z}=\frac{\beta \rho \tau_{0}\left(Z_{0}\right)^{-\beta} l^{H}}{(1-\phi)\left\{\psi\left[1-\tau_{0}\left(Z_{0}\right)^{-\beta}\right]+\varepsilon(1-\sigma)(\psi+\rho)\right\}}, \\
l^{X}=1-l^{H}-l^{Z}, \\
c_{t}=X_{t}=\frac{A l^{X} H_{t}}{N}, \quad E_{t}=N X_{t}\left(Z_{t}\right)^{-\beta}, \quad Z_{t}=Z_{0} \exp \left\{g_{Z} t\right\}, \quad H_{t}=H_{0} \exp \left\{g_{H} t\right\} .
\end{gathered}
$$

Growth rates of quantities:

$g_{H}=g_{H^{X}}=g_{H^{Z}}=g_{H^{H}}=\psi l^{H}, \quad g_{c}=g_{X}=g_{H}, \quad g_{Z}=\frac{g_{H}}{1-\phi} \quad g_{E}=g_{H}\left(1-\frac{\beta}{1-\phi}\right)$.

Prices:

$$
\begin{gathered}
p=\frac{1}{A\left[1-\tau_{0}\left(Z_{0}\right)^{-\beta}\right][1+(\alpha-1) / Q]}, \\
v_{t}=\frac{\beta \tau_{0}\left(Z_{0}\right)^{-\beta} l^{X}}{\left[1-\tau_{0}\left(Z_{0}\right)^{-\beta}\right][1+(\alpha-1) / Q]} \frac{H_{t}}{Z_{t}}+\frac{\phi g_{Z}}{\delta\left(Z_{t}\right)^{\phi}},
\end{gathered}
$$




$$
\begin{aligned}
V_{t} & =\frac{1}{\delta\left(Z_{t}\right)^{\phi}}, \\
r & =g_{c}+\rho .
\end{aligned}
$$

Growth rates of prices:

$$
g_{p}=g_{r}=0, \quad g_{v}=g_{V}=-\phi g_{Z}
$$

Number of firms in each sector:

$$
Q=\frac{(1-\alpha)\left(1-l^{H}\right)}{l^{Z}}
$$

Proof. See Appendix.

Proposition 1, shows that a positive growth of consumption per-capita is compatible with a cleaner environment. One has $g_{c}>0$ and $g_{E}<0$ if $1-\beta /(1-\phi)<0$. If the government does not intervene, i.e. $\tau_{0}=0$, firms do not employ any human capital to conduct research: $l^{Z}=0$, so no research is conducted to attempt to reduce pollution emissions. The reason is simply that firms do not have incentives to spend funds in a costly activity which is not profitable. In this case, the positive growth rate of consumption goes along with a more polluted environment: $g_{E}>0$.

In this economy, human capital accumulation is the ultimate engine of growth. The main interesting result is the possibility for the government to modify the long-run value of growth through a change of environmental policy. Proposition 1 shows that the equilibrium value of the share of human capital devoted to education, $l^{H}$, depends on $\tau_{0}$. Thus, a change in the level of the environmental policy induces individuals to modify their choice of education. In turn, this affects the long-run level of growth of consumption per-capita because $g_{c}=g_{H}=\psi l^{H}$. ${ }^{6}$ We study the effects of environmental policy changes on the steady-state in the next sub-section.

\subsection{Effects of environmental policy changes}

We assume that the economy has reached the balanced growth path, and the government decides to implement a permanent, marginal increase in $\tau_{0}$. The effect on the variables are summarized in Table 1 which presents the signs of the derivatives of $l^{H}, l^{Z}, l^{X}, p, r, Q$,

\footnotetext{
${ }^{6}$ In a R\&D-based model with endogenous population growth, Jones (2003) describes a similar mechanism. He shows that a subsidy to research affects growth through their effects on the choice of fertility of individuals.
} 
$g_{c}$ with respect to the policy instrument $\tau_{0}$. The proofs of the results are direct when we examine Proposition 1.

\section{Table 1}

About here

From Table 1, an increase of the tax on pollution, $\tau_{0}$, leads to an increase of the share of human capital devoted to $\mathrm{R} \& \mathrm{D}, l^{Z}$, a decrease of the share of human capital devoted to the production of differentiated goods, $l^{X}$, a higher price for differentiated goods, $p$, and a reduction of the number of firms in each sector, $Q$. The effect on the share of human capital devoted to education, $l^{H}$, so on the long-run growth rate of consumption, $g_{c}$, and on the interest rate, $r$, depends on the desire of individuals to acquire education, $\varepsilon$. The intuition for these results is as follows.

When the policy-maker increases the level of the policy instrument, firms have an incentive to reduce their pollution emissions. Then, they employ more human capital for research activities, and reduce the quantity they employ for the production of the goods: $l^{Z}$ is higher and $l^{X}$ is lower. The primary effect is an improvement of the price of differentiated goods, $p$, and a diminution of the number of firms in each sector, $Q$.

To understand the effect of policy changes on the decisions of individuals to acquire skills on the growth rate of consumption and on the interest rate, it is convenient to recall equation (14): $\psi+\varepsilon \psi\left(1-\sigma_{j t}\right) p_{j t} \sum_{j=1}^{N}\left(c_{j t}\right)^{\alpha} /\left[H_{t}\left(c_{j t}\right)^{\alpha-1}\right]=r$. Using Proposition 1 , this equation shows that policy changes affect the non-pecuniary part of the return to education (second term on the left hand side), i.e. the utility gains obtained from the consumption of education. Therefore, when $\varepsilon>0$, the willingness of individuals to acquire skills is altered. Basically, individuals face a higher price for differentiated goods. So, they prefer to 'consume' more education because the cost of education relative to consumption is lower. They allocate a larger share of their time to educational activities, $l^{H}$. This drives the interest rate, $r$, and the growth rates of human capital, $g_{H}$, and consumption, $g_{c}$, up.

When $\varepsilon=0$, education does not affect the level of utility of individuals. The return to investment in education is constant and independent of the policy instrument: $\psi=r$. Thus, the decision of individuals to acquire skills are not altered by policy changes. The steady-state growth rate of human capital obtained is the same as in Lucas (1988). The 
more effective education is, i.e. the larger $\psi$ is, the higher are $g_{H}, g_{Z}, g_{c}$. However, as before, the policy change induces firms to reduce the amount of human capital they use to produce the differentiated goods and to employ more human capital to produce knowledge. This leads to an increase of the market price for differentiated goods and to a reduction of the number of firms operating in each sector. In the meantime, the environment is cleaner.

\subsection{Implementation of optimum}

Before to compute the exact values of the policy tools which allow the government to maximize welfare, it is necessary to characterize the optimal balanced growth path. The problem of the social planner is to maximize (5) subject to (1), (2), (3), (4), (6), (7). In this problem, the number of firms in each sector, $Q$, is taken as given. The results are summarized in Proposition 2.

Proposition 2 An optimal balanced growth path is characterized by a set of shares of human that satisfy the following system of three equations:

$$
\begin{gathered}
l^{X}+l^{Z}+l^{H}=1, \\
\frac{\beta \omega l^{X} \psi l^{H}}{(1-\omega)(1-\phi) l^{Z}}=\psi l^{H}+\rho, \\
\frac{\varepsilon \psi l^{X}}{(1-\omega)}+\psi=\psi l^{H}+\rho .
\end{gathered}
$$

Quantities are:

$$
c_{t}=X_{t}=\frac{A l^{X} H_{t}}{N}, \quad E_{t}=N X_{t}\left(Z_{t}\right)^{-\beta}, \quad Z_{t}=Z_{0} \exp \left\{g_{Z} t\right\}, \quad H_{t}=H_{0} \exp \left\{g_{H} t\right\} .
$$

Growth rates are:

$$
g_{H}=\psi l^{H}, \quad g_{c}=g_{X}=g_{H}, \quad g_{Z}=\frac{g_{H}}{1-\phi} \quad g_{E}=g_{H}\left(1-\frac{\beta}{1-\phi}\right) .
$$

Proof. See Appendix.

Now, we can compute the levels of the policy tools that allow the government to implement the optimum. Comparing the results at equilibrium (Proposition 1) and at 
optimum (Proposition 2), the value of the optimal environmental tax rate comes easily. ${ }^{7}$ Moreover, the subsidy for the demand of differentiated goods is such that the price effectively paid by individuals to consume a unit of differentiated good equals its marginal cost of production: $(1-\sigma) p=A^{-1}+p \tau_{t}\left(Z_{t}\right)^{-\beta}$. To sum-up, one has:

Proposition 3 If the government chooses

$$
\begin{gathered}
\tau_{0}=\omega\left(Z_{0}\right)^{\beta}, \\
\sigma=\frac{(1-\alpha)(1-\omega)}{Q},
\end{gathered}
$$

the balanced growth path at equilibrium is optimal.

From Proposition 3, when the policy-maker chooses the value of the subsidy rate, $\sigma$, he/she implicitly determines the number of firms operating on the market of each differentiated good. Given the fact that the environmental tax, $\tau_{0}$, is optimal, the subsidy rate, $\sigma$, is set such that the values of the shares of human capital at equilibrium match the ones computed for the optimum (Proposition 2).

One should make observe that, if individuals do not derive utility from education, $\varepsilon=0$, one single policy instrument consisting of the environmental tax, $\tau_{0}=\omega\left(Z_{0}\right)^{\beta}$, is sufficient to maximize welfare. Indeed, examination of Proposition 1 , shows that, in this particular case, the rate of subsidy $\sigma$ does not appear in quantities, prices and growth rates at the steady-state. We impose this subsidy in order to eliminate the distortion caused by imperfect competition. However, this policy tool does not modify the equilibrium values. There are two reasons for this result. First, in this case the supply of human capital to working activities (production of differentiated goods and research) is inelastic with respect to the rate of subsidy $\sigma$. Second, the Cournot competition leads to a price for differentiated goods which is above the marginal cost of production. However, the relative prices of differentiated goods are not affected by imperfect competition because of the property of symmetry of the model. Consequently, imperfect competition, alone, does not prevent optimality. ${ }^{8}$ The only distortion affecting the allocation of human capital consists of pollution externalities. The role of the environmental tax, $\tau_{0}=\omega\left(Z_{0}\right)^{\beta}$, is then

\footnotetext{
${ }^{7}$ More precisely, to obtain Proposition 3, we compare equations (20) and (21) with the equivalent ones of the equilibrium which are computed in Appendix (see equations (32) and (33), respectively).

${ }^{8}$ See Barro and Sala-I-Martin (1995, ch. 6, Section 2) who obtain a similar result in a model with an expanding variety of consumer products, but without pollution.
} 
to obtain an optimal allocation of the shares of human capital inside working activities, $l^{X}$ and $l^{Z}$.

\section{Conclusion}

This paper has investigated the implication for growth of an environmental policy. We have shown that a tighter policy can enhance growth. This is because the policy acts through the channel of education which is the only ingredient to sustain long-run economic growth. The result comes from the fact that we have treated education as a product altering the utility of individuals. This renders the supply of human capital to working activities elastic with respect to price changes, i.e. to policy changes. To conduct the analysis, we have considered an equilibrium in which knowledge is directly patented and priced. We have characterized a general equilibrium with Cournot competition and free entry. We have then derived an implementation of the optimal balanced growth path and computed the values of the policy tools that a policy-maker should use to maximize welfare.

Beyond the question treated in this paper, we think that there are some avenues for future research. For instance, one could study the transitional dynamics of the model. Several other extensions are also possible. We think that an interesting one would be to introduce a nonrenewable resource in the model: it is well known that the combustion of resources such as petroleum or coal is responsible for an important part of $\mathrm{CO}_{2}$ and the main greenhouse gas.

\section{Appendix}

\subsection{Equilibrium with Cournot competition and free entry}

We proceed in two steps. First, we compute the main conditions that emerge at date $t$ on each market. Second, we characterize the steady-state equilibrium.

1) Markets conditions for a symmetric equilibrium

On differentiated goods markets there is Cournot competition and free entry in each sector $j$. Using (15), one gets the equilibrium quantity of each differentiated good which 
is produced in each sector:

$$
X_{t}=D_{t}\left\{\frac{A\left[1-\tau_{t}\left(Z_{t}\right)^{-\beta}\right]\left[1+(\alpha-1) / Q_{t}\right]}{\left(1-\sigma_{t}\right)}\right\}^{\frac{1}{1-\alpha}} .
$$

Using (1), one gets the aggregate production function for each differentiated good:

$$
X_{t}=\frac{A H_{t}^{X}}{N}
$$

Using (3), the total flow of pollution emissions is:

$$
E_{t}=N X_{t}\left(Z_{t}\right)^{-\beta}
$$

Equations (12) and (22) yield the Cournot equilibrium price for each differentiated good $j$ :

$$
p_{t}=\frac{1}{A\left[1-\tau_{t}\left(Z_{t}\right)^{-\beta}\right]\left[1+(\alpha-1) / Q_{t}\right]} .
$$

From (18), the free entry condition is $\pi_{q_{j} t}=\widetilde{\pi_{q_{j}}}-V_{q_{j} t} \dot{Z}_{t}=0$ for all $q_{j}$ and for all $j$. Using the property of symmetry, one has $\pi_{q_{j} t}=\pi_{t}=p_{t} X_{t}\left[1-\tau_{t}\left(Z_{t}\right)^{-\beta}\right] / Q_{t}-H_{t}^{X} / Q_{t} N-$ $H_{t}^{Z} / Q_{t} N=0$ for all $q_{j}$ and for all $j$. Plugging equations (23) and (25), one gets

$$
\frac{H_{t}^{X}}{\left[1+(\alpha-1) / Q_{t}\right]}-H_{t}^{X}-H_{t}^{Z}=0
$$

Knowledge is traded using bilateral contracts. From (17), (22), (23), one gets the total willingness to pay at date $t$ to use a piece of knowledge at $t$ by all firms of the $N$ sectors:

$$
v_{t}=\sum_{j=1}^{N} \sum_{q_{j}=1}^{Q_{j t}} v_{q_{j} t}=\frac{\beta \tau_{t}\left(Z_{t}\right)^{-\beta} H_{t}^{X}}{\left[1-\tau_{t}\left(Z_{t}\right)^{-\beta}\right]\left[1+(\alpha-1) / Q_{t}\right] Z_{t}}+V_{t} \phi \delta H_{t}^{Z}\left(Z_{t}\right)^{\phi-1}
$$

Equation (16) gives the willingness to pay to use a piece of knowledge from $t$ to infinity by all firms of the $N$ sectors:

$$
V_{t}=\int_{t}^{\infty} v_{s} e^{-\int_{t}^{s} r_{u} d u} d s=\frac{1}{\delta\left(Z_{t}\right)^{\phi}}
$$

From (2), the aggregate law of motion of knowledge is

$$
\dot{Z}_{t}=\delta H_{t}^{Z}\left(Z_{t}\right)^{\phi}
$$


which yields $g_{Z_{t}}=\delta H_{t}^{Z}\left(Z_{t}\right)^{\phi-1}$ for all $t$.

The financial market is perfectly competitive. Using equation (13) with the assumption of symmetry, on gets the value of the interest rate:

$$
r_{t}=g_{c_{t}}+\rho+g_{p_{t}}+g_{\left(1-\sigma_{t}\right)}=v_{t} / V_{t}+g_{V_{t}} .
$$

Finally, the labor market is perfectly competitive and clears. At each instant, one has $H_{t}=H_{t}^{X}+H_{t}^{Z}+H_{t}^{H}$, which yields

$$
1=l_{t}^{X}+l_{t}^{Z}+l_{t}^{H}
$$

when we divide by $H_{t}$.

2) Steady-State

Recall that $\sigma$ is independent of $t$. Thus, $g_{(1-\sigma)}$ is equal to zero.

Prices:

The prices and their growth rates follow directly from (25), (27), (28), (30).

Levels of quantities and their growth rates:

The quantities are given by (4), (22), (23), (24), (29). Their growth rates are easily computed by differentiation. Moreover, equation (4) implies that $g_{H}=\psi l^{H}$ at each moment since $l^{H} \equiv H_{t}^{H} / H_{t}$.

Using $r_{t}=\dot{V}_{t} / V_{t}+v_{t} / V_{t}$ with $l_{t}^{X} \equiv H_{t}^{X} / H_{t}, l_{t}^{Z} \equiv H_{t}^{Z} / H_{t},(27),(28),(29)$, (30) and the value of the growth rates obtained above, one gets

$$
\psi l^{H}+\rho=\frac{\beta g_{Z} \tau_{t}\left(Z_{t}\right)^{-\beta}}{\left[1-\tau_{t}\left(Z_{t}\right)^{-\beta}\right][1+(\alpha-1) / Q]} \frac{l^{X}}{l^{Z}} .
$$

Applying the property of symmetry to equation (14) and using $l^{X} \equiv H_{t}^{X} / H_{t}(23),(25)$, (30) with the value of the growth rates obtained above, one gets

$$
\psi l^{H}+\rho=\psi+\frac{\varepsilon \psi(1-\sigma) l^{X}}{\left[1-\tau_{t}\left(Z_{t}\right)^{-\beta}\right][1+(\alpha-1) / Q]} .
$$

Number of firms, $Q$, that composes each sector $j$ :

Dividing the free entry condition in each sector (26) by $H_{t}$, one gets

$$
\frac{l^{X}}{[1+(\alpha-1) / Q]}=l^{X}+l^{Z} \text {. }
$$


Equations (31), (32), (33), (34) constitute a system of four equations with four unknowns $\left(l^{X}, l^{Z}, l^{H}, Q\right)$ that can be used to determine the values given in Proposition 1. To find $l^{H}$, we combine (32) and (34) and use the fact that $l^{X}+l^{Z}=1-l^{H}$ (see $(31))$. To find $l^{Z}$, we equate the right hand side of (32) and (33) and, as before, we replace $l^{X} /[1+(\alpha-1) / Q]$ by $1-l^{H}$ (see (31)). Using the value of $l^{H}$, one computes $1-l^{H}=\rho\left[1-\tau_{0}\left(Z_{0}\right)^{-\beta}\right] /\left\{\psi\left[1-\tau_{0}\left(Z_{0}\right)^{-\beta}\right]+\varepsilon \psi(1-\sigma)\right\}$. Thus, one finds $l^{Z}=\beta \rho \tau_{0}\left(Z_{0}\right)^{-\beta} g_{Z} /\left\{\psi^{2}\left[1-\tau_{0}\left(Z_{0}\right)^{-\beta}\right]+\varepsilon \psi(1-\sigma)(\psi+\rho)\right\}$. Replacing $g_{Z}$ by its value computed previously $\left(g_{Z}=\psi l^{H} /(1-\phi)\right)$, one gets the value of $l^{Z}$ given in Proposition 1 . This value is given as a function of $l^{H}$ for convenience. Finally, the values of $l^{X}$ and $Q$ follow directly from (31) and 34 .

Note that equations (32) and (33) require that the term $\tau_{t}\left(Z_{t}\right)^{-\beta}$ is constant, i.e. we must have $\tau_{t}\left(Z_{t}\right)^{-\beta} \equiv \tau_{0}\left(Z_{0}\right)^{-\beta}$ at any time at steady-state.

\subsection{Optimum}

At optimum, the number of firms in each sector, $Q_{j}$, is given. The problem of the social planner is to maximize (5) subject to the aggregate production process of differentiated good $j\left(X_{j t}=\sum_{q_{j}=1}^{Q_{j}} X_{q_{j}}=A H_{j t}^{X}\right)$, the aggregate production process of knowledge $\left(\dot{Z}_{t}=\right.$ $\left.\sum_{j=1}^{N} \sum_{q_{j}=1}^{Q_{j}} \dot{Z}_{q_{j} t}=\delta H_{t}^{Z}\left(Z_{t}\right)^{\phi}\right)$, the flow of pollution emissions $\left(E_{t}=\sum_{j=1}^{N} \sum_{q_{j}=1}^{Q_{j}} E_{q_{j} t}=\right.$ $\left.\sum_{j=1}^{N} X_{j t}\left(Z_{t}\right)^{-\beta}\right)$ and the human capital constraint $(7)$. The current value Hamiltonian of the problem is

$$
\begin{aligned}
C V H= & \ln \left[\sum_{j=1}^{N}\left(c_{j t}\right)^{\alpha}\right]^{1 / \alpha}+\varepsilon \ln H_{t}-\omega \ln \sum_{j=1}^{N} A H_{j t}^{X}\left(Z_{t}\right)^{-\beta}+\sum_{j=1}^{N} \lambda_{j t}\left[A H_{j t}^{X}-c_{j t}\right]+ \\
& \mu_{t} \phi \delta H_{t}^{Z}\left(Z_{t}\right)^{\phi}+\nu_{t} \psi H_{t}^{H}+\xi_{t}\left[H_{t}-\sum_{j=1}^{N} H_{j t}^{X}-H_{t}^{A}-H_{H}^{t}\right],
\end{aligned}
$$

where $\lambda_{j t}(j=1, \ldots, N), \mu_{t}, \nu_{t}$ are co-state variables.

The first order conditions are: $\partial C V H / \partial c_{j t}=0, \partial C V H / \partial H_{j t}^{X}=0, \partial C V H / \partial H_{t}^{Z}=0$, $\partial C V H / \partial H_{t}^{H}=0, \partial C V H / \partial Z_{t}=-\dot{\mu}_{t}+\rho \mu_{t}, \partial C V H / \partial H_{t}=-\dot{\nu}_{t}+\rho \nu_{t}$. The transversality conditions are $\lim _{t \rightarrow \infty} \mu_{t} Z_{t} e^{-\rho t}=0$ and $\lim _{t \rightarrow \infty} \nu_{t} H_{t} e^{-\rho t}=0$. We look for a symmetric optimum: $\lambda_{j t}=\lambda_{t}$ for all $j$. The first order conditions are: $1 / c_{t}=\lambda_{t} N(\mathrm{a}),-\omega / H_{t}^{X}+\lambda_{t} N X_{t} / H_{t}^{X}=\xi_{t}$ (b), $\mu_{t} \dot{Z}_{t} / H_{t}^{Z}=\xi_{t}(\mathrm{c}), \nu_{t} \psi=\xi_{t}(\mathrm{~d}), \beta \omega / Z_{t}+\mu_{t} \phi \dot{Z}_{t} / Z_{t}=-\dot{\mu}_{t}+\rho \mu_{t}$ (e), $\varepsilon / H_{t}+\xi_{t}=$ $-\dot{\nu}_{t}+\rho \nu_{t}$ (f). The transversality conditions are $\lim _{t \rightarrow \infty} \mu_{t} Z_{t} e^{-\rho t}=0$ and $\lim _{t \rightarrow \infty} \nu_{t} H_{t} e^{-\rho t}=0$. 
The growth rates are $g_{H}=\psi l^{H}, g_{c}=g_{X}=g_{H}, g_{Z}=g_{H} /(1-\phi), g_{E}=g_{H}[1-\beta /(1-$ $\phi)]$.

Let us divide (e) by $\mu_{t}$ and (f) by $\nu_{t}$. One gets $\beta \omega / \mu_{t} Z_{t}+\phi g_{Z}=-\dot{\mu}_{t} / \mu_{t}+\rho$ (e') and $\varepsilon / \nu_{t} H_{t}+\xi_{t} / \nu_{t}=-\dot{\nu}_{t} / \nu_{t}+\rho\left(\mathrm{f}^{\prime}\right)$. Manipulation of (a) and (b) with the condition $c_{t}=X_{t}$ yields $1 /\left(\xi_{t} H_{t}\right)=H_{t}^{X} /\left[(1-\omega) H_{t}\right](\mathrm{g})$. Manipulation of (c), (d) and (g) yields $1 / \mu_{t} Z_{t}=g_{Z} H_{t}^{X} /\left[(1-\omega) H_{t}^{Z}\right](\mathrm{h})$. Thus, from (a), (e'), (f'), (g), (h), one deduces $-g_{\lambda}=g_{c}$, $-g_{\mu}=g_{Z},-g_{\nu}=-g_{\xi}=g_{H}$ (i). Manipulation of (c), (e'), (h), (i) yields

$$
\frac{\beta \omega l^{X} \psi l^{H}}{(1-\omega)(1-\phi) l^{Z}}=\psi l^{H}+\rho .
$$

Manipulation of (d), (e'), (f), (h) yields

$$
\frac{\varepsilon \psi l^{X}}{(1-\omega)}+\psi=\psi l^{H}+\rho .
$$

The two previous equations and the human capital constraint can be used to determine the shares of human capital devoted to each sector of the economy.

\section{Acknowledgements}

We would like to thank Juntip Boonprakaikawe and one anonymous referee for their helpful comments and suggestions. The second author thanks Nottingham University (UK) for its support during the redaction of this paper.

\section{References}

Aghion, P. and Howitt, P., 1992. A model of growth through creative destruction, Econometrica. 60:323-351.

Aghion, P. and Howitt, P., 1998. Endogenous Growth Theory. Cambridge, MA: MIT Press.

Arnold, L., 1998. Growth, welfare, and Trade in an Integrated Model of HumanCapital Accumulation and Research, Journal of Macroeconomics. 1:84-105.

Arrow, K.J., 1962. Economic Welfare and the Allocation of Resources for Inventions, in Richard R. Nelson ed. The Rate and Direction of Inventive Activity. Princeton University Press and NBER. 
Barro, R.J. and Sala-I-Martin, X., 1995. Economic Growth. New-York: McGraw-Hill.

Blackburn, K., Hung, V.T.Y. and Pozzolo, A.F., 2000. Research, Development and Human Capital Accumulation, Journal of Macroeconomics. 22:189-206.

Boonprakaikawe, J. and Tournemaine, F., 2006. Production and Consumption of Education in a R\&D-based Growth Model, Scottish Journal of Political Economy, 53:565585.

Bovenberg, A.L. and Smulders, S., 1995. Environmental quality and pollution-augmenting technological change in a two-sector endogenous growth model. Journal of Public Economics. 57:369 391.

Carraro, C. and Siniscalco, D., 1994. Environmental Policy reconsidered: the role of technology innovation, European Economic Review. 38:545-555.

Dalgaard, C. J. and Kreiner, C. T., 2001. Is Declining Productivity inevitable?, Journal of Economic Growth. 6:187-203.

Dasgupta, P., Mäler, K.G., Navaretti, G.B. and Siniscalco, D., 1996. On Institutions that Produce and Disseminate Knowledge. Mimeo.

van Ewijk, C. and van Wijnbergen, S., 1994. Can abatement overcome the conflict between environment and economic growth? De Economist, 143:197-216.

Feehan, J.P., 1989. Pareto-efficency with Three Varieties of Public Inputs, Public Finance. 2:237-248.

Funke, M. and Strulik, H., 2000. On endogenous growth with physical capital, human capital and product variety, European Economic Review. 44:491-515.

Gallini, N. and Scotchmer, S., 2003. Intellectual Property: When is it the Best Incentive System? in Innovation Policy and the Economy, Vol 2, Adam Jaffe, Joshua Lerner and Scott Stern (editors), MIT Press, pp. 51-78, and also forthcoming in Legal Orderings and Economic Institutions, F. Cafaggi, A. Nicita and U. Pagano (editors), Routledge Studies in Political Economy.

Grimaud, A., 1999. Pollution Permits and Sustainable Growth in a Schumpeterian Model, Journal of Environmental Economics and Management. 38:249-266.

Grimaud, A. and Rouge, L., 2005. Polluting Non-renewable Resources, Innovation and Growth: Welfare and Environmental Policy, Resource and Energy Economics. 27:109-129.

Grossman, G.M. and Helpman, E., 1991. Quality ladders in the theory of growth, Review of economic studies. 58:557-586.

Hart, R., 2004. Growth, Environment and Innovation - a model with production 
vintages and environmentally oriented research. Journal of Environmental Economics and Management, 48:1078-1098.

Jones, C.I., 1995. R\&D-Based Models of Economic Growth, Journal of Political Economy. 105:759-784.

Jones, C.I., 2003. Population and Ideas: A Theory of Endogenous Growth, in 'Knowledge, Information, and Expectations in Modern Macroeconomics', in Honor to Edmund S. Phelps, Philippe Aghion, Roman Frydman, Joseph Stiglitz, and Michael Woodford (editors).

Kaizuka, K., 1965. Public Goods and Decentralization of Production, Review of Economics and Statistics. 47:118-120.

Lucas, R.E., 1988. On the Mechanics of Economic Development, Journal of Monetary Economics. 22:3-42.

Ligthart, J.E. and van der Ploeg, F., 1994. Sustainable Growth and Renewable Resources in the Global Economy. in C. Carraro Ed., Trade, Innovation, Environment, Kluwer Academic, Netherlands.

Manning, R., Markusen, J.R. and Mc Millan, J., 1985. Paying for Public Inputs,American Economic Review. 75:235-238.

Mas-Colell, A., Whinston, M.D. and Green, J.R., 1995. Microeconomic Theory. Oxford University Press.

Oueslati, W., 2002. Environmental policy in an endogenous growth model with human capital and endogenous labor supply. Economic Modelling, 19:487-507.

Peretto, P., 1998. Technological Change and Population Growth, Journal of Economic Growth. 3:283-311.

Peretto, P., 1999a. Cost Reduction, Entry, and the Interdependence of Market Sructure and Economic Growth. Journal of Monetary Economics, 43:173-195.

Peretto, P., 1999b. Firm Size, Rivalry and the Extent of the Market in Endogenous Technological Change. European Economic Review, 43:1747-1773.

Porter, M.E. and van der Linde, C., 1995. Toward a new conception of the environment competitiveness relationship. Journal of Economic Perspectives, 9:97-118.

Quah, D.T., 1997. Increasingly Weightless Economy. Bank of England Quarterly Bulletin, 37:27-59.

Quah, D.T., 2001. The Weightless Economy in Economic Development. Ch. 4 in Information Technology, Productivity and Economic Growth: International Evidence, 
ed. Matti Pohjola, Oxford University Press.

Romer, P., 1990. Endogenous Technological Change. Journal of Political Economy, 98:S71-S102.

Sandmo, A., 1972. Optimality Rules for the Provision of Collective Factors of Production, Journal of Public Economics, 1, 149-157.

Scotchmer, S., 1991. Standing on the Schoulders of Giants: Cumulative Research and the Patent Law, Journal of Economic Perspective, Symposium on Intellectual Property Rights.

Scotchmer, S., 1999. Cumulative Innovations in Theory and Practice. Working paper, U.C., Berkeley.

Scotchmer, S., 2005. Innovation and Incentives. Cambridge, MA: MIT Press.

Schou, P., 2002. Pollution Externalities in a Model of Endogenous Fertility and Growth. International Tax and Public Finance, 9:709-725.

Schultz, T., 1963. The Economic Value of Education. New-York: Columbia University Press.

Smulders, S. and van de Klundert T., 1995. Imperfect Competition, Concentration and Growth with Firm-Specific R\&D. European Economic Review, 39:139-160.

Smulders, S. and van de Klundert T., 1997. Growth, Competition and Welfare, Scandinavian Journal of Economics. 99:99-118.

Stokey, N., 1998. Are there limits to growth? International Economic Review, 39:1-31.

Strulik, H., 2005. The Role of Human Capital and Population Growth in R\&D-Based Models of Economic Growth. Review of International Economics, 13:129-145.

Tirole, J., 1988. The Theory of Industrial Organization. Cambridge, MA: MIT Press.

Varian, H.R., 1998. Markets for Information Goods. Mimeo, draft October 16, 1998. 